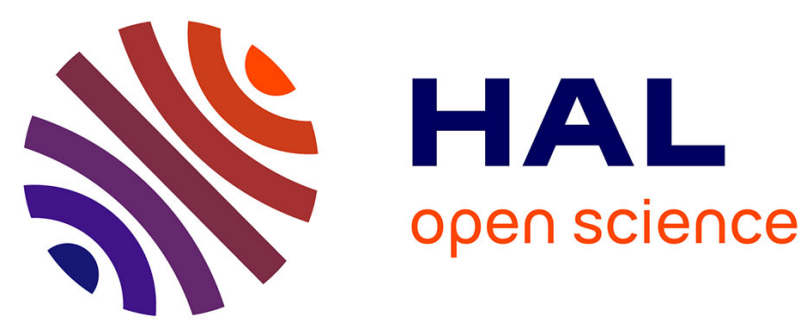

\title{
Remote oxidative modifications induced by oxygen free radicals modify $T / R$ allosteric equilibrium of a hyperthermophilic lactate dehydrogenase
}

Frédéric Halgand, Chantal Houée-Lévin, Martin Weik, Dominique Madern

\section{- To cite this version:}

Frédéric Halgand, Chantal Houée-Lévin, Martin Weik, Dominique Madern. Remote oxidative modifications induced by oxygen free radicals modify $T / R$ allosteric equilibrium of a hyperthermophilic lactate dehydrogenase. Journal of Structural Biology, 2020, 210 (2), pp.107478. 10.1016/j.jsb.2020.107478 . hal-03011827

\section{HAL Id: hal-03011827 \\ https://hal.science/hal-03011827}

Submitted on 3 Dec 2020

HAL is a multi-disciplinary open access archive for the deposit and dissemination of scientific research documents, whether they are published or not. The documents may come from teaching and research institutions in France or abroad, or from public or private research centers.
L'archive ouverte pluridisciplinaire HAL, est destinée au dépôt et à la diffusion de documents scientifiques de niveau recherche, publiés ou non, émanant des établissements d'enseignement et de recherche français ou étrangers, des laboratoires publics ou privés. 


\title{
Remote oxidative modifications induced by oxygen free radicals modify $T / R$ allosteric equilibrium of a hyperthermophilic lactate dehydrogenase
}

\author{
Frédéric Halgand ${ }^{\mathrm{a}}$, Chantal Houée-Lévin ${ }^{\mathrm{a}}$, Martin Weik ${ }^{\mathrm{b}}$, Dominique Madern ${ }^{\mathrm{b}, *}$ \\ ${ }^{a}$ Université Paris Sud-CNRS, UMR 8000, bâtiments 201 P2 and 350, 91405 Orsay, France \\ ${ }^{\mathrm{b}}$ Univ. Grenoble Alpes, CEA, CNRS, IBS, 38000 Grenoble, France
}

\section{A R T I C L E I N F O}

\section{Keywords:}

Lactate dehydrogenase

Allosteric regulation

Mass spectrometry

Extremophilic protein

Ion mobility

Oxidative stress

\begin{abstract}
A B S T R A C T
L-Lactate dehydrogenase (LDH) is a model protein allowing to shed light on the fundamental molecular mechanisms that drive the acquisition, evolution and regulation of enzyme properties. In this study, we test the hypothesis of a link between thermal stability of LDHs and their capacity against unfolding induced by reactive oxygen species (ROS) generated by $\gamma$-rays irradiation. By using circular dichroism spectroscopy, we analysed that high thermal stability of a thermophilic LDH favours strong resistance against ROS-induced unfolding, in contrast to its psychrophilic and mesophilic counterparts that are less resistant. We suggest that a protein's phenotype linking strong thermal stability and resistance against ROS damages would have been a selective evolutionary advantage. We also find that the enzymatic activity of the thermophilic LDH that is strongly resistant against ROS-unfolding is very sensitive to inactivation by irradiation. To address this counter-intuitive observation, we combined mass spectrometry analyses and enzymatic activity measurements. We demonstrate that the dramatic change on LDH activity was linked to remote chemical modifications away from the active site, that change the equilibrium between low-affinity tense (T-inactive) and high-affinity relaxed (R-active) forms. We found the T-inactive thermophilic enzyme obtained after irradiation can recover its LDH activity by addition of the allosteric effector 1, 6 fructose bis phosphate.

We analyse our data within the general framework of allosteric regulation, which requires that an enzyme in solution populates a large diversity of dynamically-interchanging conformations. Our work demonstrates that the radiation-induced inactivation of an enzyme is controlled by its dynamical properties.
\end{abstract}

\section{Introduction}

Extreme environments such as temperature, pressure and radiation or desiccation, salinity, $\mathrm{pH}$ and redox potential exert strong physical and/or chemical constraints on organisms' adaptation and fitness (Rothschild and Mancinelli, 2001). With respect to high temperature, the present-day habitats of (hyper) thermophilic microorganisms' mimics conditions encountered in primitive hot archaean oceans (Nisbet and Sleep, 2001). At the cellular level, numerous studies show that thermophilic organisms are capable to resist strong doses of ionizing radiation (IR) (Ranawat and Rawat, 2017). When exposed to IR, cells are damaged by direct and indirect effects. Most of the damages are indirect and are induced by water radiolysis, which produces reactive oxygen species (ROS). The capacity of cells to thrive in strong IR environment was analyzed to be the consequence of important DNA repair capacity, ROS detoxification mechanisms and accumulation of protective solute such as trehalose (Ranawat and Rawat, 2017). In contrast, the putative favorable relationship between thermal stability of cell macromolecules (in particular proteins) and resistance to oxidative stress resulting from irradiation is not documented.

Reactive oxygen species (ROS) are highly deleterious for cellular macromolecules (nucleic acids, lipid, and proteins) leading to important cell damage. These ROS induce various kinds of damage to biological macromolecules, such as DNA base modifications and strand breakage, lipid peroxidation, protein oxidation and enzyme inactivation (For reviews see (Aruoma et al., 1991; Halliwell and Gutteridge, 1999; Houée-Levin and Bobrowski, 2013)). Proteins are strongly sensitive to ROS attacks since they have a low reduction potential. One of

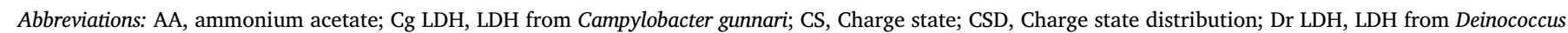

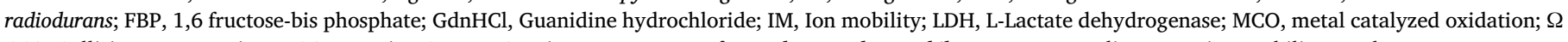
CCS, Collision cross section; ROS, Reactive Oxygen Species; Tt LDH, LDH from Thermus thermophiles; TWIM, Traveling wave ion mobility; Z, charge state

*Corresponding author at: Institut de Biologie Structurale, Campus EPN CS 10090, 71 avenue des Martyrs, 38044 Grenoble Cedex 9, France.

E-mail address: dominique.madern@ibs.fr (D. Madern). 
the most common chemical mechanisms responsible for protein oxidation in vivo relies on metal-catalyzed oxidation (MCO) mainly induced by copper and iron ions. (For a recent review related to oxidative stress processes see (Cheignon et al., 2018)). The most common chemical oxidant used to probe oxidative stress on proteins is hydrogen peroxide $\left(\mathrm{H}_{2} \mathrm{O}_{2}\right)$ in the presence or absence of metals. The nature of oxidation products and location are usually documented using the coupling of biochemical methods with mass spectrometry (Requena et al., 2004; Wolschner et al., 2009). Unfortunately, experimental conditions to produce MCO are often not biologically relevant. In addition, they do not reflect the dynamics and responsiveness of enzymatically produced ROS in vivo. In this context, it is possible to use a ${ }^{60} \mathrm{Co} \gamma$-radioactive source to generate selected ROS in controlled amounts (Vogt, 1995). The fine tuning of the nature of the produced ROS is achieved by controlling solution parameters (chemical composition of the solution, concentration of the various components, $\mathrm{pH}$, deoxygenation...) and their total amount by irradiation time (Alvarez et al., 2010; Brun et al., 2010; Et Taouil et al., 2014; Kadlick et al., 2004). Acting on these various parameters allows better mimicking in vivo of oxidative stress conditions than MCO. ROS such as $\mathrm{H}_{2} \mathrm{O}_{2}$, superoxide anion $\left(\mathrm{O}_{2}{ }^{-}\right)$, singlet oxygen $\left({ }^{1} \mathrm{O}_{2}\right)$ and the hydroxyl radical (' $\mathrm{OH})$ are produced in oxidative-stress conditions and under exposure of aqueous solutions to VUV, ultrasound, and ionizing radiation (von Sonntag, 2008). The concentration of ${ }^{\circ} \mathrm{OH}$ in vivo might be in the range of $10^{-10}$ to $10^{-12}$ mol. $\mathrm{L}^{-1}$ for instantaneous ROS bursts, while cumulative ROS concentrations could reach $10^{-6}$ to $10^{-4} \mathrm{~mol} . \mathrm{L}^{-1}$. They react with most biological compounds on the ns time scale or faster (For review see: (Aruoma et al., 2006; Bobrowski, 2017; Hardy et al., 2018; Houée-Levin and Bobrowski, 2013; Kalyanaraman et al., 2018) and references therein). Numerous studies based on the characterization of individual oxidized proteins have shown that ROS alter their properties either by cleavage of the peptide bonds, cross-linking between protomers or by modification of side chain residues. (Reviewed by Cecarini et al., (Cecarini et al., 2007) and Avery, (Avery, 2011))

In the present work we address the question of whether or not the intrinsic stability of an enzyme prevents its ROS induced impairment. This is an important issue, because if a positive correlation would exist, this would have been one of the selective advantages allowing to cope with harsh conditions occurring in primitive environments.

To achieve this goal, we compared the conformational stability and enzymatic properties after exposure to ROS produced by $\gamma$ irradiation of several lactate dehydrogenases (LDH) taken as model enzymes. LLactate dehydrogenases (LDHs) (EC 1.1.1.27) are important enzymes involved in energy metabolism. They have been purified from a variety of organisms and their structures, function and evolution have been analyzed in detail (Madern, 2002). LDHs are active tetramers of identical 30-35 kDa subunits. Most of the bacterial enzymes are allosteric displaying homotropic activation by the pyruvate and heterotopic activation by fructose 1,6-bisphosphate (FBP) (Taguchi, 2017). In contrast, eukaryotic LDHs are considered as non-allosteric.

We used LDHs from organisms (Champsocephalus gunnari $(\mathrm{Cg})$, deinococcus radiodurans (Dr) and thermus thermophilus (Tt)) living in different thermal environment considered as cold, mesophilic and thermophilic, respectively. Their biochemical properties and crystal structures were described. The melting temperature $\left(\mathrm{T}_{\mathrm{M} 1 / 2}\right)$ of $\mathrm{Cg} \mathrm{LDH}$ is $50{ }^{\circ} \mathrm{C}$, it is $60{ }^{\circ} \mathrm{C}$ for $\mathrm{Dr} \mathrm{LDH}$ and $90{ }^{\circ} \mathrm{C}$ with $\mathrm{Tt} \mathrm{LDH}$ (Coquelle et al., 2007). The strong thermal stability of Tt LDH was analyzed to be the consequence of a high number of ionic networks compared to its counterpart. By disrupting some of these stabilizing interactions, using site-directed mutagenesis the $\mathrm{T}_{\mathrm{M} 1 / 2}$ of the resulting mutant (Tt LDH-5 mut) was shifted downward by $20{ }^{\circ} \mathrm{C}$ (Colletier et al., 2012). This Tt LDH mutant was also used in our investigation.

The effects of ROS were monitored by circular dichroism spectroscopy, mass spectrometry and enzymatic activity. In contrast to its psychrophilic and mesophilic counterparts, for which deactivation and unfolding are concomitant, Tt LDH is still folded even after exposure to high radiation doses, whereas it loses its activity at very low dose. Such a discrepancy of ROS effects between orthologous enzymes demonstrates that loss of activity and change in conformational stability (unfolding) are not necessarily coupled.

To shed light on this peculiar phenomenon, we continued our investigations on $T t \mathrm{LDH}$ by considering its allosteric properties. Indeed, Tt LDH is considered as a good representative of allosteric LDHs (Colletier et al., 2012; Coquelle et al., 2007; Taguchi, 2017). The native tetrameric state has four catalytic sites and two FBP-binding sites. The $T t$ LDH obey the allosteric transition according to the Monod-WymanChangeux (MWC) model, where the active (R) and inactive (T) states of the enzyme coexist in an allosteric equilibrium (pre-existing equilibrium) independently of allosteric effectors. The effect of irradiation on $T t$ LDH equilibrium was investigated using ion mobility mass spectrometry (IM-MS). IM-MS provides a measure of the average collision cross section (CCS) of proteins. This parameter is related to the shape and ionization state of proteins during their travel in the nitrogen gas buffer of the mass spectrometer (Scarff et al., 2008). CCS variations of proteins are strongly correlated to conformational changes observed using X-ray crystallographic data (Jurneczko and Barran, 2011). We depict the Tt LDH conformational landscape variation upon irradiation using a graphical representation: $\Omega=\mathrm{f}(\mathrm{z})$ graphs, in which $\Omega$ is the collisional cross section ( $\Omega=$ CCS, $\AA^{2}$ ), and z the charge state (CS). In addition, we show that enzymatic activity of the ROS-inactivated Tt LDH can be restored by addition of the small allosteric effector FBP. We discuss the implications of these findings in the light of the allosteric control of LDH activity.

\section{Materials and methods}

\subsection{Materials}

Trypsin, GdnHCl and ammonium acetate were purchased from Sigma Aldrich. TSK $3000 \mathrm{SW}$ gel filtration column $(1 \times 300 \mathrm{~mm})$ was obtained from Interchim.

\section{Methods}

\subsection{Protein purification}

Purifications of LDHs from Campylobacter gunnari $(\mathrm{Cg})$, Deinococcus radiodurans $(D r)$ and of wild type and mutant $T t$ LDH were carried out according to protocols described earlier (Colletier et al., 2012; Coquelle et al., 2007).

\subsection{Thermal denaturation}

Several samples of each LDH species were diluted to a final concentration of $0.1 \mathrm{mg} / \mathrm{ml}$ in $50 \mathrm{mM}$ Tris- $\mathrm{HCl}, \mathrm{pH} 7$ and incubated for $30 \mathrm{~min}$ at various constant temperatures. Eight different temperatures were tested over a range from 20 to $95^{\circ} \mathrm{C}$. After thermal treatment, the samples were then centrifuged to remove aggregates induced by unfolding and their CD spectrum was recorded at $25{ }^{\circ} \mathrm{C}$, on a Jobin Yvon CD6 circular dichroism spectropolarimeter using a quartz cuvette with a path-length of $0.1 \mathrm{~cm}$. The spectra were recorded at $50 \mathrm{~nm} / \mathrm{min}$ with a bandwidth of $2.0 \mathrm{~nm}$ and an integration time of $6 \mathrm{sec}$, over the wavelength range 190-260 $\mathrm{nm}$. The fraction of folded enzyme was calculated using the pre- and post-transition baseline slope normalization of CD values recorded at $222 \mathrm{~nm}$ (Coquelle et al., 2007).

\subsection{Protein irradiation}

All the LDHs tested, were dissolved to a final concentration of $0.1 \mathrm{mg} / \mathrm{mL}(0.8 \mu \mathrm{M})$ in $50 \mathrm{mM}$ Tris- $\mathrm{HCl} \mathrm{pH}$ 7. They were irradiated in air atmosphere in the panoramic ${ }^{60} \mathrm{Co} \gamma$-source IL60PL (Cis-Bio International (France)) at the University Paris-Sud (Orsay, France). The 
absorbed dose was determined by Fricke dosimetry (Spinks and Woods, 1990). The doses were comprised between 10 and $1500 \mathrm{~Gy}$. Interaction of ionizing radiations with water leads to the formation of free radicals following equation (1):

$\mathrm{H}_{2} \mathrm{O} \rightarrow \mathrm{OH}, \quad \mathrm{H}^{\cdot}, \quad e_{\mathrm{aq}}^{-}, \mathrm{H}_{2}, \mathrm{H}_{2} \mathrm{O}_{2}, \mathrm{H}^{+}, \mathrm{OH}^{-}$

In air atmosphere, $\mathrm{H}^{*}$ and $e_{\mathrm{aq}}^{-}$are scavenged by oxygen leading to the formation of superoxide ions or the acidic form $\mathrm{HO}_{2}$ according to equations (2) and (3):

$e_{\mathrm{aq}}^{-}+\mathrm{O}_{2} \rightarrow \mathrm{O}_{2}^{--}$

$\cdot \mathrm{H}+\mathrm{O}_{2} \rightarrow \mathrm{HO}_{2}$

Thus, the solutes can react with ${ }^{\circ} \mathrm{OH}$ and $\mathrm{O}_{2}{ }^{-}$- radicals (with respective yields of 0.27 or $0.33 \mu \mathrm{mol} / \mathrm{J}$ ). Their total amounts are proportional to the dose, i.e. the total [ $\left.{ }^{\circ} \mathrm{OH}\right]$ delivered to the solution was between 2.7 and $400 \mu \mathrm{M}$. The $\mathrm{H}_{2} \mathrm{O}_{2}$ yield is lower $\left(0.07 \mu \mathrm{mol} \mathrm{J}{ }^{-1}\right)$. In the presence of Tris buffer, $\mathrm{OH}$ radicals can react either with the protein or with the buffer, the latter reaction having a rate constant $\mathrm{k}_{4}=1.510^{9} \mathrm{~mol}^{-1} \mathrm{~L} \mathrm{~s}^{-1}$ as exemplified in equation (4):

Tris $+\cdot \mathrm{OH} \rightarrow$ Tris $\cdot(-\mathrm{H})+\mathrm{H}_{2} \mathrm{O}$ (Hicks and Gebicki, 1986)

Tris does not react with superoxide ions.

Assuming the rate constants of the reaction of ${ }^{\circ} \mathrm{OH}$ radicals with the proteins is $\mathrm{K}_{5}$ equal to $2 \times 10^{10} \mathrm{~mol}^{-1} \mathrm{~L} \mathrm{~s}^{-1}$, which is a low value for proteins (NIST database), in air atmosphere the scavenging ratio of the protein toward ${ }^{\circ} \mathrm{OH}$ radicals is equal to:

$\frac{K_{5}[L D H]}{K_{4}[\text { Tris }]}=\frac{210^{10} \times 310^{-3}}{1.510^{9} \times 0.05}=8$

Hence, the percentage of $\mathrm{OH}$ radicals reacting with the protein is equal to $44 \%$ (or higher than this value if $k_{5}$ is larger). Reaction (4) produces carbon-centered radicals that are usually poorly reactive toward proteins. In our case the use of phosphate buffer (which reacts more slowly with ${ }^{\circ} \mathrm{OH}$ radicals and thus scavenges very few ${ }^{\circ} \mathrm{OH}$ radicals) was not possible. Indeed, as it has been found with certain LDHs (Feldman-Salit et al., 2013), we observed that phosphate buffer has a very strong activating effect on enzymatic activity, suggesting it favors the $\mathrm{T}$ active state of $\mathrm{Tt} \mathrm{LDH}$, a phenomenon which would have prevented the effect of ${ }^{\circ} \mathrm{OH}$ radicals on the R-inactive state as presented below. The measurements were carried out in triplicate at $20{ }^{\circ} \mathrm{C}$. Some aliquots of each LDH were tested before and after irradiation using the standard enzymatic assay.

For samples prepared for mass spectrometry experiments Tt LDH concentration was $90 \mu \mathrm{M}$ in Tris- $\mathrm{HCl} 50 \mathrm{mM}, \mathrm{pH}$ 7. Oxygen was removed by bubbling $\mathrm{N}_{2} \mathrm{O}$ in the solution. The presence of $\mathrm{N}_{2} \mathrm{O}$ yields a higher ${ }^{\circ} \mathrm{OH}$ production (Hicks and Gebicki, 1986). Samples were irradiated during time intervals corresponding to 100, 200 and $350 \mathrm{~Gy}$ (that corresponds to the total production of 54,108 and $189 \mu \mathrm{M}$ of ${ }^{\circ} \mathrm{OH}$ radicals in these conditions) and separated in size-exclusion chromatography (SEC).

\subsection{Enzymatic assays}

The assay was performed at $30^{\circ}, 45{ }^{\circ} \mathrm{C}$ and $70{ }^{\circ} \mathrm{C}$ with $\mathrm{Cg}, \mathrm{Dr}$ and $\mathrm{Tt}$ $\mathrm{LDH}$, respectively. These temperatures were chosen below their apparent optimum temperature as previously determined (Coquelle et al., 2007). At high temperature, data were corrected for thermal instability of pyruvate and NADH. The standard assay mixture of $1.0 \mathrm{ml}$ contained $0.2 \mathrm{mM} \mathrm{NADH}, 0.6 \mathrm{mM}$ pyruvate and $50 \mathrm{mM}$ Tris- $\mathrm{HCl} \mathrm{pH}$ 7. The reaction was started by the addition of the enzyme solution and LDH activity was immediately followed during $20 \mathrm{sec}$ by monitoring the decrease of NADH absorbance $(A)$ at $340 \mathrm{~nm}$ in a Beckman DU 7400 spectrophotometer.

\subsection{Residual activity measurements}

After irradiation, equivalent aliquots of the various LDHs under investigations were tested in the standard enzymatic assay. Then, the $\mathrm{d} A / \mathrm{d} t$ values were recorded. To assess the effect of FBP on Tt LDH activity before and after irradiation, the measurements were performed both in the standard assay (without FBP) and in the standard assay supplemented with $0.5 \mathrm{mM}$ FBP. The values were expressed in percentage by comparison with those recorded on untreated enzymes. Such a method allows comparing directly the effects of different treatments on activity.

\subsection{Size-exclusion chromatography (SEC) coupled to mass spectrometry} (MS)

SEC-MS coupling was set up using a TSK 3000 SW gel filtration column (Interchim, $1 \times 300 \mathrm{~mm}$ ). Elution buffer was $20 \mathrm{mM}$ ammonium acetate, $\mathrm{pH} \mathrm{7}$, infused at $0.02 \mathrm{ml} / \mathrm{min}$ flow rate and directly injected in the electrospray ionization source. Ten $\mu \mathrm{l}$ of standard and irradiated protein solution initially at $100 \mu \mathrm{M}$ concentration were loaded on the SEC column.

\subsection{Tryptic digestion}

For digestion, $10 \mu \mathrm{L}$ of each LDH sample (irradiated and non-irradiated control) were added to $100 \mu \mathrm{L}$ of $100 \mathrm{mM}$ ammonium acetate, $\mathrm{pH} 7$, containing $20 \%$ acetonitrile and $1 \mathrm{M}$ Gdn- $\mathrm{HCl}$. To this solution $10 \mu \mathrm{L}$ of trypsin at $1 \mu \mathrm{g} / \mu \mathrm{L}(\mathrm{E} / \mathrm{S}=1 / 3)$ was added and LDH samples were digested overnight at $37{ }^{\circ} \mathrm{C}$. Note that under standard conditions using various ratio between trypsin and the target protein (1/200 to 1/ 50 and without $\mathrm{Gdn}-\mathrm{HCl}$, nor acetonitrile) no digestion was observed.

\subsection{Mass spectrometry analyses}

Mass spectrometry experiments were performed on a QToF instrument (Synapt G2-Si, Waters Company, Manchester, UK). Acquisition of mass spectra was carried out over the $m / z 500$ to 14,000 range and analyzed in the positive ion mode under native conditions. For native experiments, instrumental and hardware parameters were optimized to reach the best average signal-to-noise ratio, while preserving intact quaternary and tertiary structures. In the meantime, ion mobility data were also recorded with the view to obtain qualitative and quantitative conformational information on irradiated proteins. Parameters are reported in supplementary material. For tryptic peptides analyses, $10 \mu \mathrm{L}$ of digested samples were injected on a C18 reverse phase column (Acquity UPLC BEH C18 $1.7 \mu \mathrm{m}, 2.1 \times 50 \mathrm{~mm}$, Waters) and separated using a linear gradient from 5 to $50 \%$ acetonitrile in $8 \mathrm{~min}$, and from 50 to $100 \%$ in $1 \mathrm{~min}$, using a flow rate of $0.6 \mathrm{ml} / \mathrm{min}$. Acquisition of mass spectra was carried out over the $m / z 500$ to 3500 range and in the positive ion mode. For tandem mass spectrometry (MSMS) experiments, data were recorded automatically using the DDA mode (Data Dependent Analysis), using or not an inclusion mass list for tandem mass spectrometry analyses of selected peptides proposed to contain chemical modifications promoted by $\gamma$-irradiation.

\subsection{Analysis of ion mobility data}

After recording ion mobility data, we searched for a way to merge the information obtained from ion mobility experiments (conformational profile and relative abundances of conformers) with information known on the protein (e.g. molecular weight) under study. To that purpose the peak detection procedure of Driftscope ${ }^{\mathrm{TM}}$, that extracts all information related to the full experiment, using a resolution of 2000 and a signal threshold detection of 2000 counts, was used to generate a raw data file (Apex3D.csv file) containing all information (e.g. $m / z, t_{d}$, intensities and collisional cross sections (CCS, $\Omega$ )) of the peaks 
identified in the experiment. Then a custom-made script allowed extracting information only related to the protein of interest by entering its average molecular mass, the $m / z$ accuracy and limits of the charge states distribution based on the information extracted from MassLynx ${ }^{\mathrm{TM}}$. In the resulting plots $(\Omega=\mathrm{f}(\mathrm{z})$ ) one can clearly observe that some charge states seem related to other neighboring charge states forming series of points that we will denote as conformer families and linked using a curve (see Fig. 5). Note that CCS reflect the accessible surface $\left(\AA^{2}\right)$ of the protein to the neutral gas in the ion mobility cell. In this display mode, we intend to convey that a single solution-phase conformation is expected to lead to a gas phase charge state distribution with CCS that should be closely related, and with a progression in CCS related to an increase in volume due to increased coulombic repulsion as charge states increase (see for instance (Beveridge et al., 2014)). This term is not very accurate as one could expect that several conformations might be present in a single conformer family. Calibration of TWIM based systems to provide absolute collision cross section for proteins is still an issue (Bush et al., 2012; Salbo et al., 2012; Sun et al., 2016) and this article does not aim to resolve it. Since no external data are available that would require absolute collisional cross section determination, the focus of this article is mostly on the changes observed in the measured collisional cross-sections. This procedure is detailed in the following reference (Van der Rest et al., 2017).

\subsection{Miscellaneous}

Calculation of protein solvent accessible surface was done using ERAIMOL (http://www.ccp4.ac.uk). The in house script for MS data analysis is accessible using https://github.com/guillaume-van-der-rest/ PickApex3D.

\section{Results}

Effect of free radical doses on the conformational stability of LDH isolated from various thermally adapted organisms. According to numerous studies on hyperthermophilic proteins, their conformational stability against thermal unfolding correlates with their ability to compete against unfolding induced by high concentration of chemical denaturants (Luke et al., 2007). We extend this correlation and hypothesize that the conformational stabilities of proteins correlate with their resistance against deleterious effects of ROS. To achieve this goal, we used water radiolysis to produce ROS and selected ${ }^{\circ} \mathrm{OH}$ radicals as the main reactive species using the well-established method of chemical scavengers (Spinks and Woods, 1990).

To test our hypothesis, we monitored the change in circular dichroism spectra as a function of the irradiation dose using a hyperthermophilic LDH from Thermus thermophilus (Tt LDH), a mesophilic LDH from Deinococcus radiodurans ( $D r$ LDH) and a psychrophilic LDH from Campylobacter gunnari ( $C g \mathrm{LDH})$. Their purification, thermal stabilization properties and crystal structure have been described earlier (Hardy et al., 2018). The thermal stability is lowest for Cg LDH and highest for Tt LDH (Coquelle et al., 2007). For all the enzymes tested here, the shape of the spectrum before irradiation, displays both strong negative amplitude at $222 \mathrm{~nm}$ and strong positive amplitude around $195 \mathrm{~nm}$, which reflects a typical folded protein (Fig. 1). In panel A, all spectra are superimposable showing that $T t \mathrm{LDH}$ fold is not impacted by irradiation up to a dose of $2000 \mathrm{~Gy}$. We noticed that Tt LDH was completely unfolded after irradiation with $4000 \mathrm{~Gy}$ (ca. $2.4 \mathrm{mM} \cdot \mathrm{OH}$ ) (not shown). In panel B, the data show that $D r$ LDH is strongly sensitive to irradiation. The spectra recorded after irradiation at 200 and $500 \mathrm{~Gy}$ show strong changes in molar ellipticity values that are typical for those observed for unfolded proteins. In panel C, $C g$ LDH spectra indicate that the enzyme is still folded after irradiation at $232 \mathrm{~Gy}$. At $1400 \mathrm{~Gy}$ the enzyme is unfolded.

${ }^{1}$ In the framework of our hypothesis, a thermo-sensitive Tt LDH mutant would be unfolded under irradiation at lower dose compared to the wild type enzyme. In a previous work, we designed a $T t \mathrm{LDH}$ mutant (5-Mut Tt LDH) in which several salt-bridges networks were disrupted (Colletier et al., 2012). This mutant displays a thermal unfolding transition lowered by $20^{\circ} \mathrm{C}$ compared to the Wt $T t$ LDH (Colletier et al., 2012). As expected, the unfolding transition curve of the mutant, monitored by CD spectroscopy, is shifted toward lower dose (Fig. 1d) demonstrating that the deleterious effect of ROS on the Tt LDH structure depends on its intrinsic conformational stability.

Our data show that the hyperthermophilic Tt LDH is more resistant against ROS induced unfolding that its mesophilic and psychrophilic counterparts. With the mesophilic and psychrophilic LDHs, it is difficult to identify a noticeable difference in the ROS unfolding effect. Taken together, the data rather suggest a threshold effect on stability rather than a gradual effect.

Effect of $\mathrm{OH}$ free radicals on LDH enzymatic activity as a function of absorbed dose. In a second set of experiments, we analyzed the effect of irradiation dose on $T t, D r$ and $C g$ LDHs by using residual activity measurements as shown in Fig. 2. The enzymatic activity of Tt LDH decreases even when irradiated at a dose as low as $20 \mathrm{~Gy}$ (ca. $1.2 \mu \mathrm{M}$ ) and is completely inactive after irradiation at doses of $150 \mathrm{~Gy}$ and above. The dose at which $50 \%$ of the enzyme was deactivated is $\mathrm{D}_{50}=55 \mathrm{~Gy}$. The mesophilic $\mathrm{Dr}$ LDH started to deactivate at $80 \mathrm{~Gy}$ and is completely inactivated after having absorbed $250 \mathrm{~Gy}$. The psychrophilic $\mathrm{Cg}$ LDH has a very similar overall deactivation profile than $\operatorname{Dr} \mathrm{LDH}$, with similar $\mathrm{D}_{50}$ values of $150 \mathrm{~Gy}$. In contrast to our CD experiments, which demonstrated that the hyperthermophilic Tt LDH was the most stable enzyme, we found that $T t$ LDH deactivates at lower irradiation doses than the other LDHs. In order to understand this phenomenon, we focused our work on Tt LDH.

Thermal stability of irradiated Tt LDH. Since the enzymatic activity of the wild-type $\mathrm{Tt} \mathrm{LDH}$ after irradiation was assessed at $70{ }^{\circ} \mathrm{C}$ (Fig. 2), we cannot exclude that the observed inactivation resulted from thermal unfolding of the irradiated enzyme. To test this possibility, we monitored the thermal stability of $T t \mathrm{LDH}$ before and after irradiation at 100 Gy using CD spectroscopy. CD spectra of non-irradiated Tt LDH recorded after incubation at various temperatures are typical of a folded protein, in the entire temperature range examined $\left(50-95{ }^{\circ} \mathrm{C}\right.$; Fig. $\left.3 \mathrm{a}\right)$. To the contrary, $\mathrm{CD}$ spectra of the irradiated enzyme indicate progressive unfolding at temperatures above $80{ }^{\circ} \mathrm{C}$ (Fig. 3b). Consequently, the data showing $\mathrm{Tt} \mathrm{LDH}$ is still folded at $70{ }^{\circ} \mathrm{C}$ after irradiation; indicate that the loss of activity is not due to unfolding.

Identification of damaged area by ROS attack in $T t \mathrm{LDH}$. In view of determining the extent of $T t$ LDH chemical modifications after irradiation with 100 and 200 Gy, Tt LDH tetramers were digested by trypsin and peptides analyzed by LC-MS and LC-MSMS. Data scrutiny allowed extracting $\mathrm{m} / \mathrm{z}$ ions that were thought to belong to modified peptides. This list was used to find modified tryptic peptides according to the following criteria: i) matching peptides must be a true tryptic peptide including or not miss-cleavages; ii) the putative modified peptide must not be observed in the control experiment; iii) mass increment measured must match with known chemical modifications; iv) peptides must contain the targeted amino-acids that were proposed to be modified. This is exemplified with the detection of a +4 Da mass increment (kynurenine) that would be confirmed only if a tryptophan residue were present in the sequence. Modified peptides are reported in Table 1. These peptides correspond to: i) 125-150, 125-170 and 319-332 peptides that were found to bear oxidations; ii) and regions 130-170, 171-180, 260-293 and 263-293 that were carbonylated on isoleucine, leucine, valine and/or proline residues. Numbering of peptide regions was done according to "structural" sequence numbering defined in (Coquelle et al., 2007). All chemical modifications are in agreement with published work on hydroxyl radical mediated

\footnotetext{
${ }^{1}$ Please, check that in all the figures legend "Tt LDH" should be written with Tt in italics.
} 


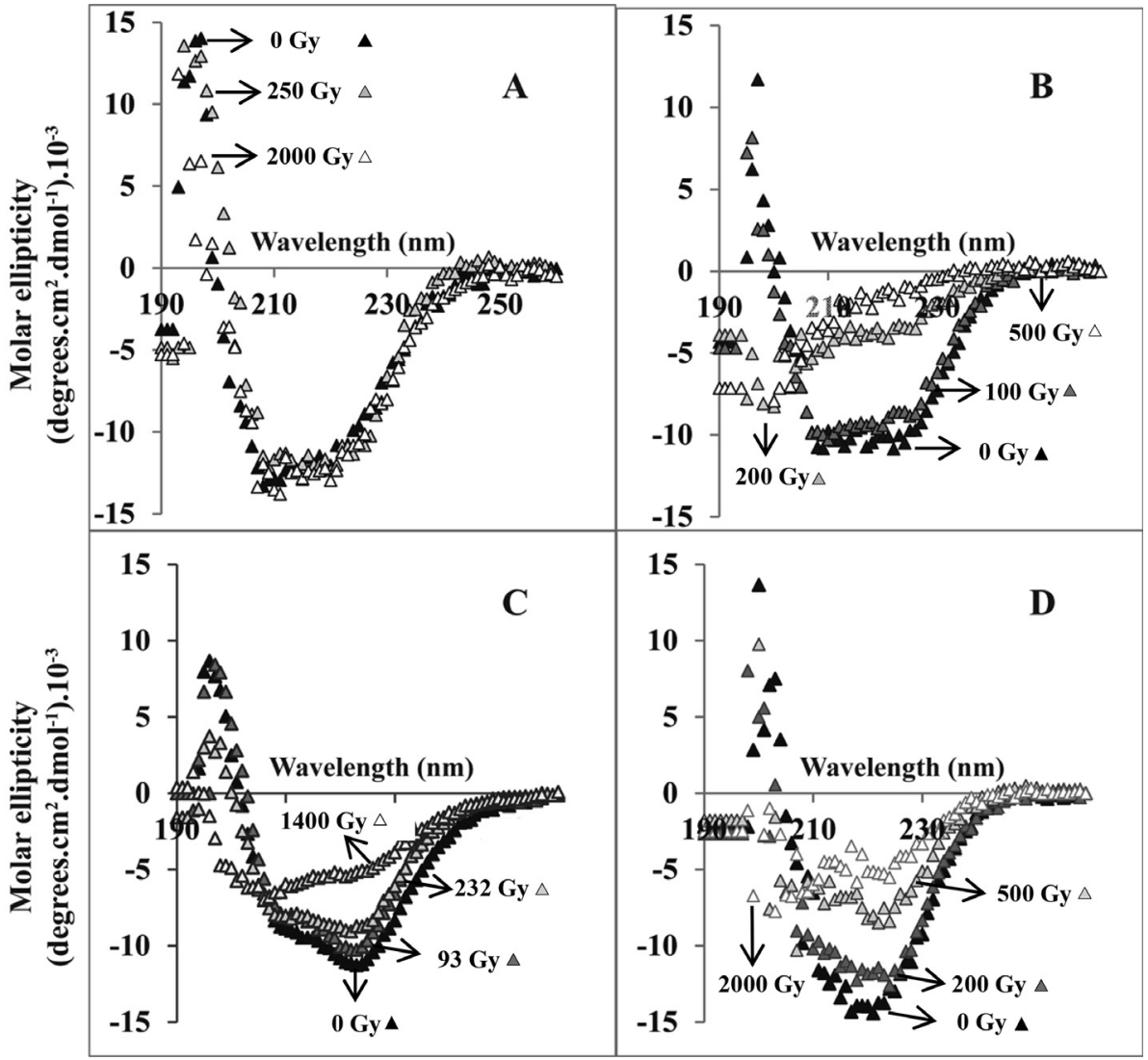

Fig. 1. Effect of irradiation on the circular dichroism spectra of various LDHs. (A) Tt LDH CD spectra recorded before (black triangles) and after irradiation at 250 (light grey triangles) and $2000 \mathrm{~Gy}$ (white triangles). (B) $\mathrm{Dr}$ LDH spectra recorded before (black triangles) and at 100 (dark grey triangles), 200 (light grey triangles) and $500 \mathrm{~Gy}$ (white triangles). (C) $\mathrm{Cg}$ LDH CD spectra recorded before (black triangles) and after irradiation at 93 (dark grey triangles), 232 (light grey triangles) and $1400 \mathrm{~Gy}$ (white triangles). (D) 5-Mut Tt LDH CD spectra recorded before (black triangles) and after irradiation at 200 (dark grey triangles), 500 (light grey triangles) and $2000 \mathrm{~Gy}$ (white triangles).

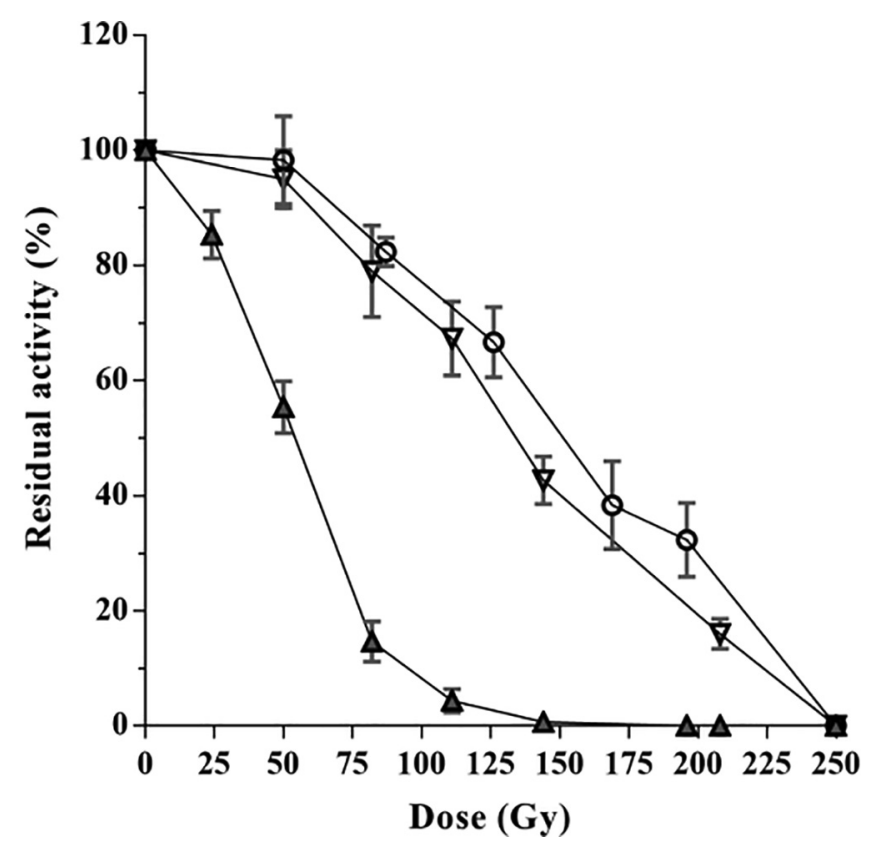

Fig. 2. Residual activity measurement of various LDH after gamma irradiation in solution. The data are normalized with respect to the activity prior to irradiation. $T t \mathrm{LDH}$ (diamonds), $\mathrm{Dr} \mathrm{LDH}$ (circles), $\mathrm{Cg} \mathrm{LDH}$ (triangles). Note that assays in triplicate were carried out at $30^{\circ}, 45{ }^{\circ} \mathrm{C}$ and $70{ }^{\circ} \mathrm{C}$ for $\mathrm{Cg}, \mathrm{Dr}$ and $\mathrm{Tt}$ $\mathrm{LDH}$, respectively (see materials-and-methods section for details).

modifications on proteins (Xu and Chance, 2007). All the sequences of the modified peptides were confirmed with identification of a sequence tag by recording MSMS spectra. However, it is obvious that mass increments can cover a plurality of chemical modifications in low amounts that were not identified here thus rendering the location of chemical modifications difficult. The T-inactive (2V6M) and R-active (2V7P) structures of Tt LDH were solved allowing the description of conformational changes observable upon substrate binding and residues involved in catalysis (Coquelle et al., 2007). The damaged areas were then analyzed with respect to this structural information.

Tt LDH loss of enzymatic activity is not due to direct damage to active-site residues. The chemical reaction catalyzed by LDHs is well documented; it involves the direct transfer of a hydride ion from C4 of the reduced nicotinamide group of NADH to $\mathrm{C} 2$ of pyruvate accompanied by the protonation of pyruvate's keto oxygen, the proton being supplied by His195 (Iwata and Ohta, 1993; Coquelle et al., 2007; Taguchi, 2017). The crystal structures of bacterial LDHs corresponding to the active (R) state have been determined in the presence of the substrate analog oxamate (Iwata and Ohta, 1993; Coquelle et al., 2007; Taguchi, 2017). They revealed interactions between important residues in the catalytic site and the substrate (Fig. 4c). In particular, the role of two arginine residues (R109 and R171) that contribute to anchor the substrate analog through a hydrogen bond and a salt bridge, respectively, has been highlighted. Other important residues are D168 that contributes to polarizing the catalytic H195, and the T245 side chain that maintains oxamate in a favorable geometry for catalysis. Upon catalysis, a mobile surface loop closes over the catalytic site promoting water expulsion from the site (not shown). In this mobile loop, Q102 plays an important role in substrate discrimination. None of these residues (Q102, R109, D168, R171, H195 and T245) are located on the ROS modified peptides identified by our mass spectrometry experiments, thus strongly suggesting the change in enzymatic activity is due to chemical modification other than in the active site.

ROS shift the Tt LDH equilibrium towards the T-inactive state. Enzymatic properties of allosteric LDHs, such as Tt LDH, obey the MWC model of allostery (Monod et al., 1965) in which low substrate affinity (T-) and high substrate affinity (R-) states are in equilibrium. In solution, the enzyme mainly samples the T-inactive state, whereas the Rstate is favored either when the substrate FBP is present, or at high 


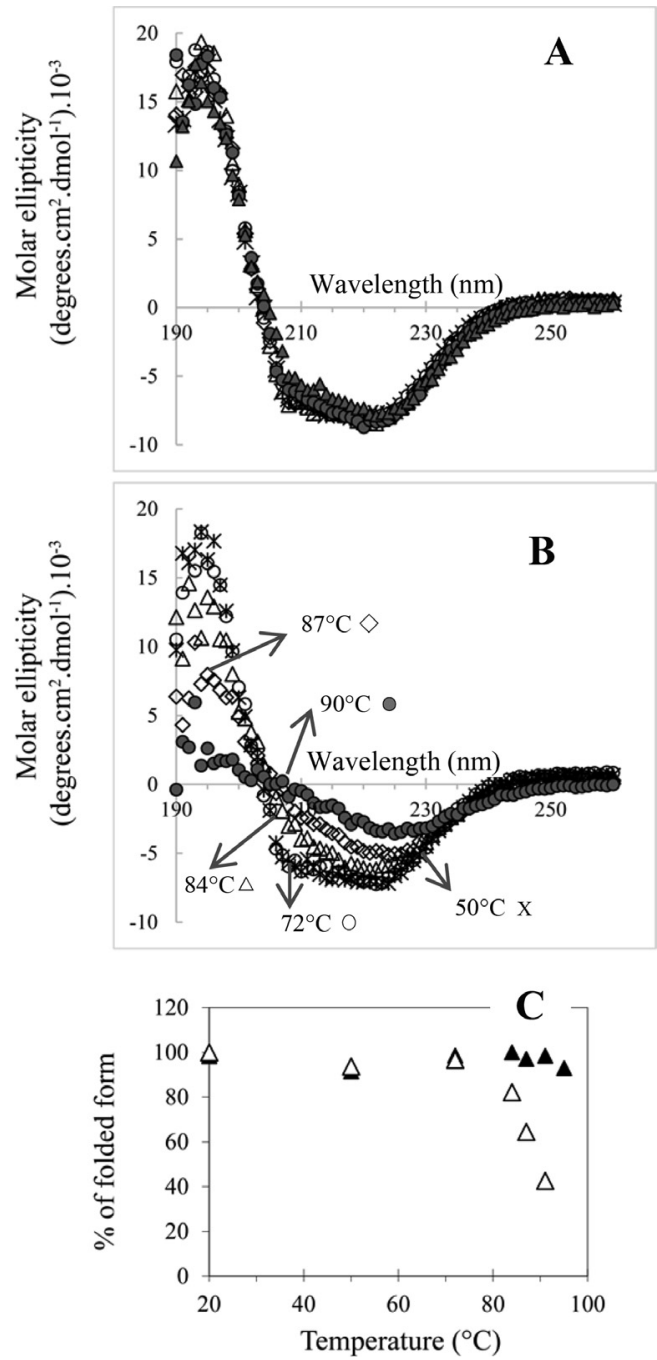

Fig. 3. Effect of irradiation on the thermal stability of Tt LDH. Spectra of nonirradiated (A) and irradiated (B) $\mathrm{Tt} \mathrm{LDH}$ were recorded after incubation at $50{ }^{\circ} \mathrm{C}$ (crosses), $72^{\circ} \mathrm{C}$ (open circle), $84^{\circ} \mathrm{C}$ (triangle), $87^{\circ} \mathrm{C}$ (square), $90^{\circ} \mathrm{C}$ (grey circle) and $95{ }^{\circ} \mathrm{C}$ (grey triangle). (C) Percentage of folded enzyme calculated from the change in the circular dichroism values at $222 \mathrm{~nm}$ with respect to values recorded at $25^{\circ} \mathrm{C}$. The closed and open triangles correspond to $T t \mathrm{LDH}$ before and after irradiation, respectively. peptides are far away from the active site and are not considered to be of major importance to explain radiation-inactivation via ROS. Two other peptides are sensitive to chemical modifications. Their location within the structure is analyzed in detail, below. The peptide in grey (residues 57-76) corresponds to helix $\alpha \mathrm{C}$ of monomer B (Fig. 4b and 4c). In the T-inactive state, the side chain of $\mathrm{H} 68$ in monomer B is in a position that prevents the side chain of R171 from accessing the active site and adopting a conformation favorable for substrate-binding (Colletier et al., 2012). The peptide in orange (residues 171-180) is involved in the local structural rearrangements of helix $\alpha 2 \mathrm{~F}$ that occurs between the T-and R-states. In the T-inactive state, helix $\alpha 2 \mathrm{~F}$ is in a position that favors the side chain of R171 being located outside the catalytic site (Colletier et al., 2012). In the R-active state, there is a rotation of the subunits that induce some helix sliding within the structure (Colletier et al., 2012). In particular, there is a relative angular displacement by $15^{\circ}$ of helix $\alpha 2 \mathrm{~F}$, which allows the lateral chain of R171 to protrude within the catalytic site (Colletier et al., 2012). This is illustrated by comparing (Fig. $4 \mathrm{~b}$ and $4 \mathrm{c}$ ). We propose that the chemical modifications (mainly oxidation and carbonylation) of these two peptides (grey and orange) prevented the Tt LDH capacity to sample its active state by strongly favoring the T-inactive state, even at a temperature of $70{ }^{\circ} \mathrm{C}$.

Radiation-inactivated $T t \mathrm{LDH}$ can be reactivated. As it is the case with allosteric LDHs, enzymatic activity of Tt LDH is sensitive to heterotropic activation by FBP (Colletier et al., 2012). We tested therefore whether or not the capacity of Tt LDH to be activated by FBP was conserved after irradiation. Recall the irradiation was done in absence of FBP and correspond to the irradiation of Tt LDH in its apo state. The residual activity measurements indicate that irradiated $T t \mathrm{LDH}$, which was inactive after irradiation when measured at $70{ }^{\circ} \mathrm{C}$ without FBP in the assay, was strongly active when the assay was performed in the presence of FBP (compare values at $150 \mathrm{~Gy}$ in Table 2). We then decided to explore if the reactivation effect of FBP was also efficient even after irradiation at higher doses. We used a slightly different protocol for the activity measurement. The results are presented in Fig. 5. The $T t \mathrm{LDH}$ was irradiated at various doses at $20{ }^{\circ} \mathrm{C}$ and several identical aliquots of each sample were monitored, at various substrate concentrations in the presence or in the absence of FBP. As expected, the non-irradiated enzyme is active (left panel, triangle), and the irradiated samples (left panel, crosses and square) are inactive when the assay is carried out at $70{ }^{\circ} \mathrm{C}$ in the presence of pyruvate and NADH. In sharp contrast, the irradiated Tt LDH is still strongly active in the presence of FBP up to a dose of $500 \mathrm{~Gy}$ (right panel, crosses and square). Above this dose the enzyme is irreversibly inactivated.

Table 1

Location of modified LDH regions. Summary of the identification of chemically modified peptides by irradiation according to structural amino-acid nomenclature.

\begin{tabular}{|c|c|c|c|c|c|}
\hline $\begin{array}{l}\text { Modified peptides identified at } 100 \text { Gy dose } \\
\text { Sequences }\end{array}$ & \multicolumn{2}{|c|}{ Peptide sequence range } & $\Delta \mathrm{m}(\mathrm{Da})$ & Chemical modifications & Misscleavage \\
\hline$\backslash$ TLEAAPEAVLLVATNPVDVMTQVAYR & 125 & 150 & 16 & mono oxidation & 0 \\
\hline PEA\TLLVATNPVDVMTQVAYRLSGLPPGRV\TGSGTILDTAR & 130 & 170 & 14 & LI,V,P carbonyl & $2^{*}$ \\
\hline FRALLAEYLR & 171 & 180 & 28 & LI,V,P carbonyl $\times 2$ & 1 \\
\hline LVRAILTDEKGVYTVSAFTPEVEG \TLEVSLSLPR & 260 & 293 & 28 & LI,V,P carbonyl $\times 2$ & 2 \\
\hline AILTDEKGVYTVSAFTPEVEGVLEVSLSLPR & 263 & 293 & 14 & LI,V,P carbonyl & 1 \\
\hline
\end{tabular}

temperature in the absence of FBP (Colletier et al., 2012; Coquelle et al., 2007). The comparison between the catalytic sites in either R- or T-states (Fig. 4b, 4c) shows that residues Q102, R109 and R102 occupy different positions. In the T-inactive state (Fig. 4c), the side chain of the main substrate binding residue R171 is oriented away from the catalytic site. The peptides identified by mass spectrometry as being impacted by ROS are highlighted in the 3D structure in different colors (Fig. 4). Two
Detection, characterization and quantification of ROS-induced changes in Tt LDH's conformational landscape. Each sample of nonirradiated and irradiated Tt LDH was injected in a size-exclusion chromatography column coupled to an ion mobility (IMS) mass spectrometer (MS) (SEC-IMS-MS). The mass spectrum indicated that nonirradiated LDH is present as a tetramer with an experimental molecular weight of $131414 \pm 200 \mathrm{Da}$; close to the expected molecular weight 
A
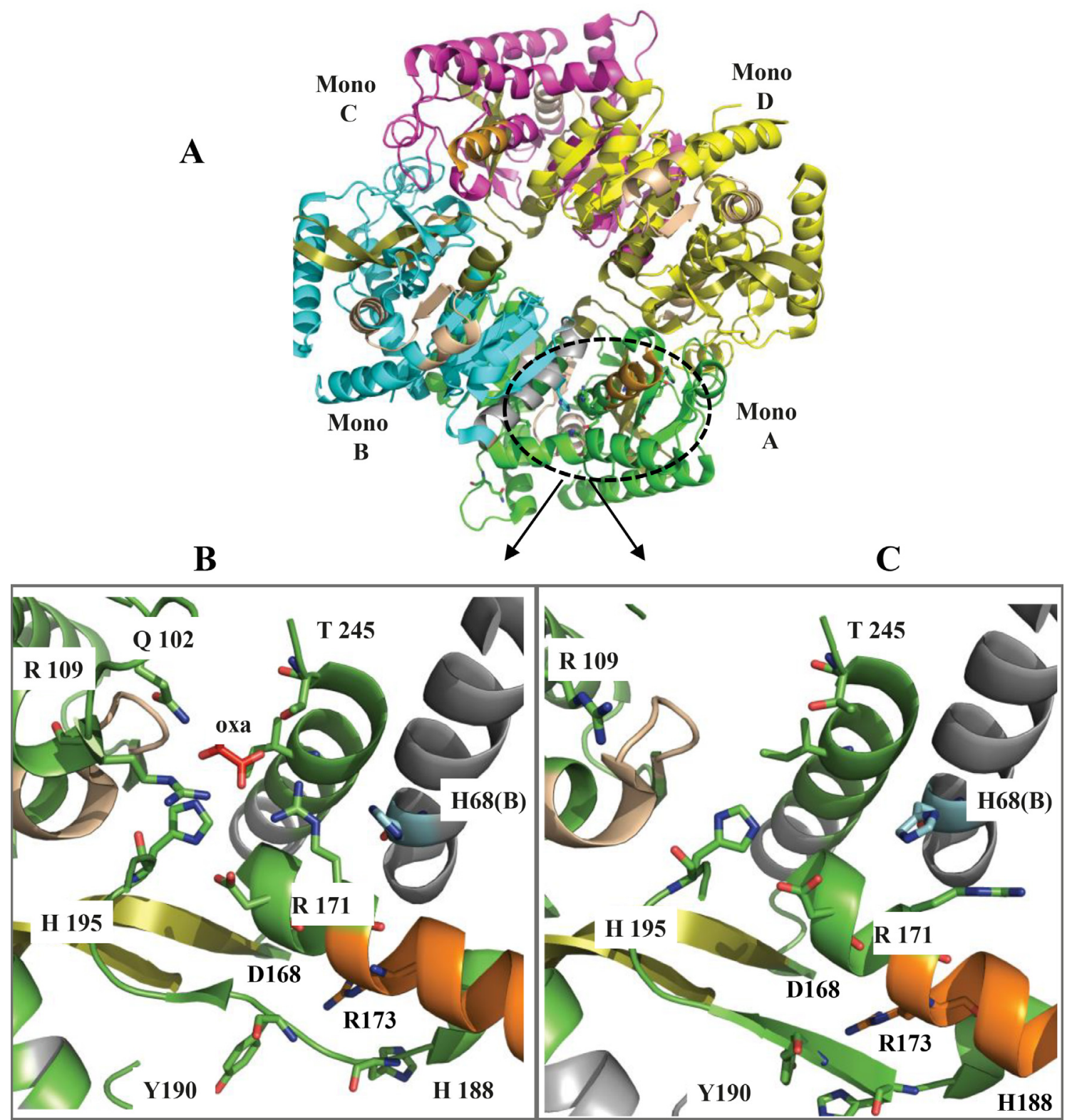

Fig. 4. Cartoon drawing of the Tt LDH tetramer with irradiated area indicated. (A) Whole Tt LDH tetramer in the inactive (T) state (PDB entry code 2V6M). The tryptic peptides impacted by ROS are colored in grey, deep olive, sand and orange for regions (57-76), (125-170), (130-180), (260-293) as well as peptide 319-332. (B) Close-up view of the active site in monomer A with a small part of monomer B (helix $\alpha \mathrm{C}$ ). This panel corresponds to the R-active state of the enzyme (PDB entry code 2V7P). The substrate analog oxamate (in orange) is anchored between Q102, T245 and R171. NADH is omitted. Residues that contributes to the FBP-binding sites i.e. R173, H188 and Y190 are also indicated. (C) Equivalent close-up view of the inactive T-state (PDB entry code 2V6M). The mobile loop which covers the catalytic site is in an open position in the inactive (T) state and therefore cannot be seen in the figure. Consequently, Q102 is far away from the position it occupies in the active (R) state.

Table 2

FBP activity recovery. Residual activity measurement showing the FBP effect on activity for irradiated and non-irradiated samples of $T t \mathrm{LDH}$.

\begin{tabular}{lll}
\hline & $\begin{array}{l}\text { \% of residual activity (no FBP } \\
\text { in the assay) }\end{array}$ & $\begin{array}{l}\% \text { of residual activity (with FBP } \\
\text { in the assay) }\end{array}$ \\
\hline Tt LDH 0 Gy & 100 & 100 \\
Tt LDH 150 Gy & 0 & 100 \\
\hline
\end{tabular}

(131 $180 \mathrm{Da}, \Delta=234 \mathrm{Da}$ ). The mass difference could be assigned to the unspecific binding of Tris, which is present in the solution used during irradiation (Table S1 and Fig. S1). The non-irradiated and irradiated Tt LDH tetramer is represented by a charge state distribution (CSD) spanning from +21 to +26 (Fig. S1). After irradiation, the data showed that the molecular weight of the tetramer increased with irradiation doses (Table S1), thus demonstrating that free radicals promote gradual chemical modifications.

To describe the structural effect of hydroxyl radicals on Tt LDH conformational landscape, we drawn: $\Omega=\mathrm{f}(\mathrm{z})$ graphs, in which $\Omega$ is the collisional cross section $\left(\Omega=\right.$ CCS, $\AA^{2}$ ), and $\mathrm{z}$ the charge state (CS) (Van der Rest et al., 2017). These plots were drawn for each irradiation dose and compared to the one corresponding to the non-irradiated enzyme (Fig. 6). Notably collisional cross sections (CCS) do not necessarily reflect solution structure of the various conformers, which are sampled by $\mathrm{Tt} \mathrm{LDH}$ in solution, nor the intensity ratios of these conformers, since data are recorded in the gas phase. Nonetheless, we can assess that colored dots (Fig. 6), reflect the relative intensities of conformers and satellite conformers (lower intensity) for a given charge state between 

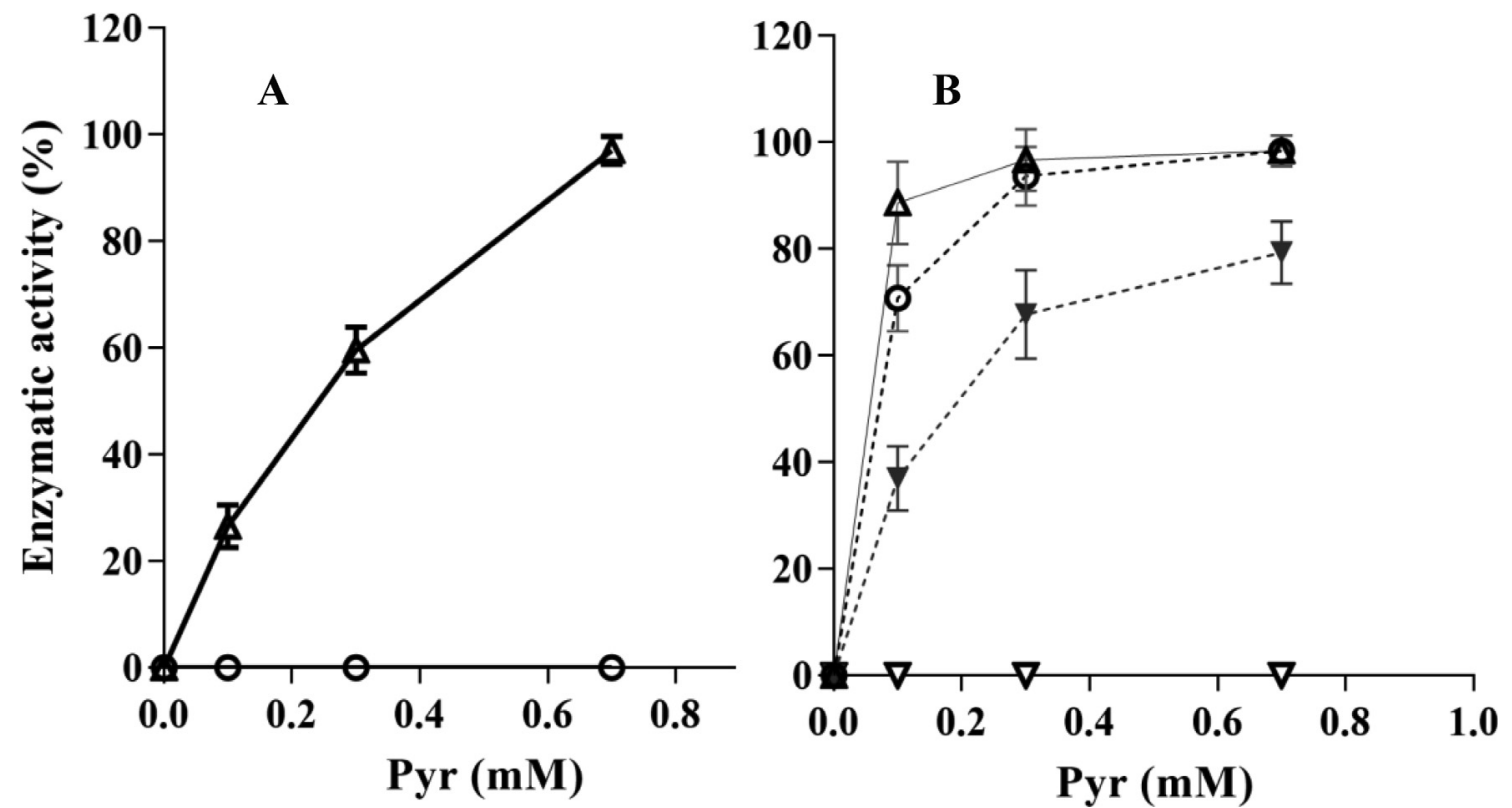

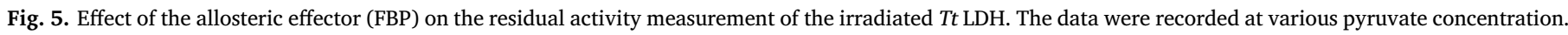

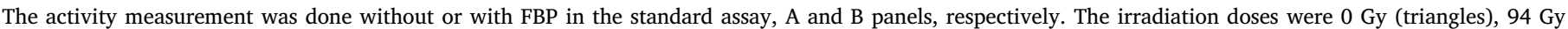
(crosses), 504 Gy (square) and 750 Gy (circle).

control and irradiated samples. To conclude, $\Omega=\mathrm{f}(\mathrm{z})$ graphs (qualitative description) and relative intensity ratios (quantitative description) allowed describing the result of irradiated samples in terms of structural properties. As observed on the $\Omega=f(z)$ graphs (Fig. 6), Tt $\mathrm{LDH}$ is at least represented by two conformers ( $\mathrm{CF} 1$ and $\mathrm{CF} 2$ ), having decreased collisional cross sections with increasing charge states (collapse of the structure). Conformers CF2 being more compact than CF1 accordingly to its lower CCS value whatever the charge state. In average, these two conformers differ in size by $9 \%$ (resolution of 3\% CCS change). The yellow dots in Fig. 6 were considered as not relevant (chemical noise). At first glance, it seems that, whatever the irradiation dose, no change appears in collisional cross section values for both conformers (CF1 and $\mathrm{CF} 2$ ). This would be due to the low resolution of these graphs that does not allow distinguishing CCS changes of low amplitude that might be significant. To investigate whether CCS changes occurred after irradiation with respect to the control sample we zoomed on each cloud of dots for each charge state. The results for two charges states (CS +23 and +24 ) is given in Fig. 6 . In this case, the satellite dots observable for each conformers CF1 and CF2 associated with both CS indicate CF1 and $\mathrm{CF} 2$ are themselves populated by discrete conformers. We calculated CCS differences between control and irradiated samples for each CS (Table S2), the results confirm that there are no significant changes induced by irradiation.

\section{Discussion}

Our aim was to analyze the effect of ROS produced by gamma irradiation on conformational stability and activity of enzymes adapted to a wide range of temperatures using LDH as a model. Under our experimental conditions, hydroxyl radicals were the main reactive oxygen species responsible for the change of LDH properties.

As a result, from CD spectroscopy measurements, we found i) that all the three wild-type LDHs ( $\mathrm{Cg}, \mathrm{Dr}$ and $\mathrm{Tt}$ ) are still folded after having absorbed $100 \mathrm{~Gy}$, i.e. ca. $62 \mu \mathrm{M} \mathrm{OH}$ radicals and ii) that at irradiation doses higher than $250 \mathrm{~Gy}$ the mesophilic and psychrophilic enzymes start to unfold, whereas Tt LDH remains folded. Recall that irradiations were performed at $25{ }^{\circ} \mathrm{C}$. Taken together, our data show that the hyperthermophilic LDH displays a peculiar response to ROS, different from the two other LDHs. We also found that the most thermostable enzyme ( $T t \mathrm{LDH}$ ) is the most sensitive to inactivation as monitored by residual activity measurements. These data allowed us to form two hypotheses. The first concerns the existence of a link between protein resistance against ROS-induced unfolding and thermal stability and the second one proposes that the loss of activity and unfolding by ROS are uncoupled.

Numerous studies have demonstrated that the high thermal stability observed with hyperthermophilic proteins is the consequence of a strong increase of complex salt bridges in their structure compared to their mesophilic and psychrophilic counterparts (Bagautdinov and Yutani, 2011; Ban et al., 2019; Kalimeri et al., 2014; Karshikoff and Ladenstein, 2001). Such a relationship also holds with the wild type Tt LDH, which has a higher number of ionic interactions compared to $\mathrm{Dr}$ and $\mathrm{Cg}$ LDHs. In $\mathrm{Tt} \mathrm{LDH}$, these additional electrostatic interactions are mainly found at the interfaces between monomers that make the tetrameric architecture (Colletier et al., 2012). In a previous study, we lowered by $20^{\circ} \mathrm{C}$ the melting temperature of $T t \mathrm{LDH}$ by disrupting these ionic networks using site-direct mutagenesis (Spinks and Woods, 1990). The fact that, the resulting Tt LDH mutant was found more susceptible to ROS-induced unfolding than the wild type enzyme lends support to the first hypothesis. However, because of the relationship between $\mathrm{Cg}$ and $\mathrm{Dr}$ LDH with respect to ROS unfolding was tenuous, we propose that the capacity to resist to this kind of unfolding is rather a threshold effect than a gradual one.

The positive correlation between the capacity to resist against ROS damage and thermal stability helps to address the question of the existence of a specific behavior of enzymes isolated from Deinococcus radiodurans. Indeed, this bacterial species that is one of the most resistant species to irradiation has been subjected to numerous investigations. These studies have shown the mechanism of resistance is induced by the high capacity of $D$. radiodurans to restore its genomic content and DNA integrity (Krisko and Radman, 2013; Spinks and Woods, 1990). Our data show the $\mathrm{Dr}$ LDH is very sensitive to ROS damage, demonstrating that there is no specific protein resistance selected by beneficial mutations in the coding sequence to compete against deleterious effects of irradiation. Nevertheless, we postulate that if there were a positive correlation between high thermal stability and resistance to ionizing radiation such a phenotype would have been favorable (a selective advantage) to maintain protein integrity in 

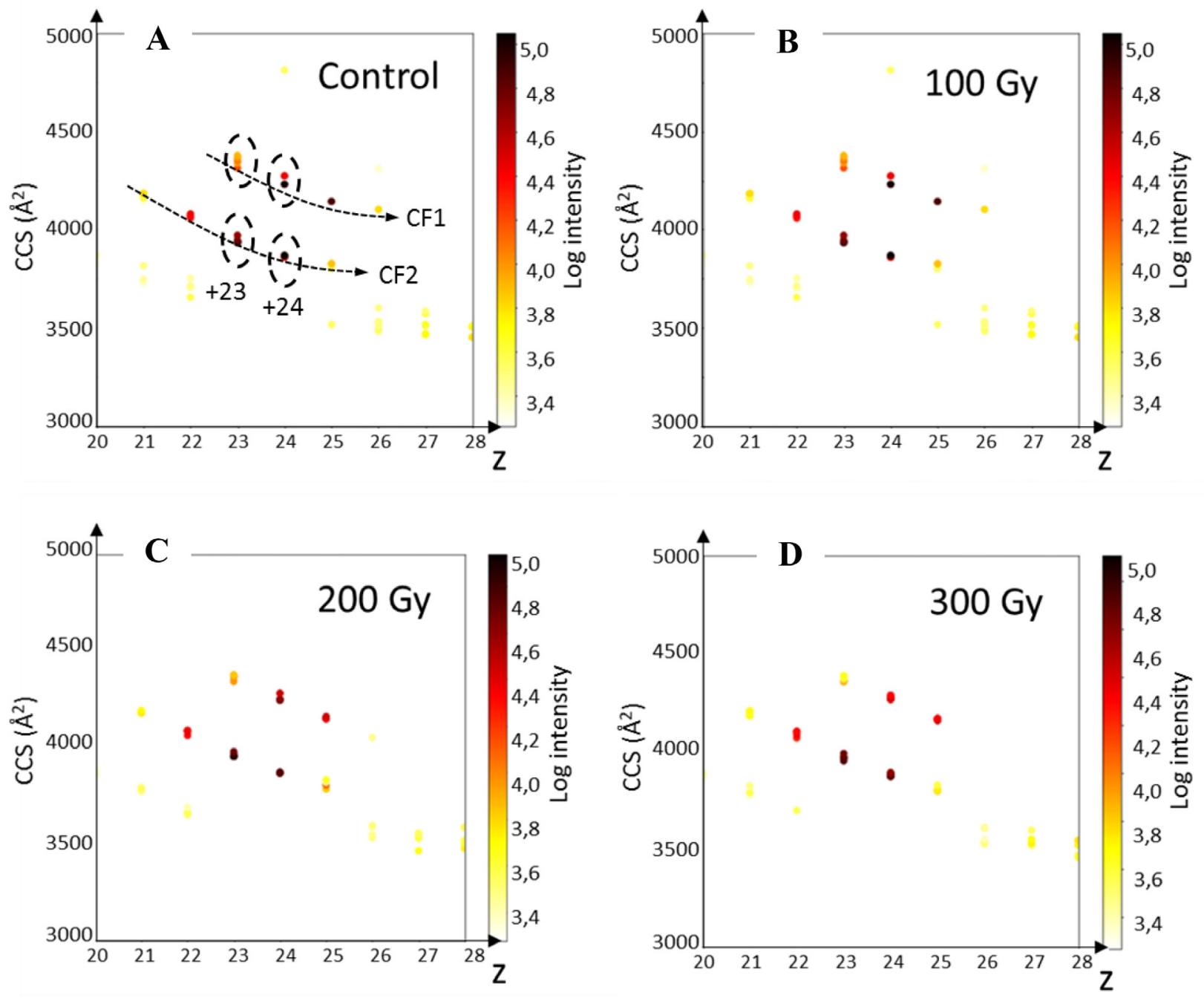

Fig. 6. Effect of irradiation on conformational landscape. $\Omega=\mathrm{f}(\mathrm{z})$ plots (CCS $=\Omega=$ collisional cross section) of the LDH tetramer under "native" conditions for control (panel A) and irradiated samples (panels B, C and D). Grouping of similar conformers families across the different charge states is labelled CF1 and CF2.

conditions of Earth's primitive environment in which ionizing radiation and radioactivity were stronger than today (Lunine, 2006). Additional experiments including resurrected ancestral proteins using a set of different enzymes would be interesting to investigate how this putative phenotype has evolved (Garcia and Kacar, 2019).

This part of the discussion addresses the second hypothesis by showing that inactivation and unfolding can be uncoupled phenomena. We found $T t$ LDH was very sensitive to inactivation even at low irradiation dose. CD spectroscopy demonstrated it was not caused by unfolding, and mass spectrometry experiments showed that the active site residues were not modified. Several studies suggested the most sensitive enzymes to ROS inactivation are those in which cysteine residues participate in the catalytic site (Buchanan and Armstrong, 1976; Chakraborty et al., 2018; Machado et al., 2017; Yan et al., 2013). Because the primary sequence of $T t \mathrm{LDH}$ indicates, there is no cysteine residue such explanation is not relevant. We continued our analysis on $T t$ LDH by using native mass spectroscopy, because it is an appropriate method to probe the dynamical properties of proteins without apparent bias towards a folded structure (Heck, 2008; McCullough et al., 2008). The resulting charge states (CS) and collisional cross sections (CCS) distributions showed that the Tt LDH conformational landscape was mainly populated by two conformers that differ by $10 \%$ in buffered gas accessible surface (CCS $\AA^{2}$ ). Native MS was demonstrated to be complementary to crystallographic studies to describe conformational changes of allosteric proteins (Beveridge et al., 2016). Therefore, we calculated the solvent accessible surfaces, based on crystallographic structures, for both the T-inactive (2V6M) and R-active (2V7P) states of Tt LDH giving values of $1324 \AA^{2}$ and $1131 \AA^{2}$, respectively. The difference of $15 \%$ between the solvent accessible surfaces of the two structures agrees with the difference of $9 \%$ between the CCS of main conformers of $T t \mathrm{LDH}$ as detected in gas phase by MS. Consequently, we can reasonably hypothesize that apo Tt LDH before irradiation is described by an equilibrium between a conformer (CF1) corresponding to the T-inactive state and another one, also inactive (CF2) which refers to the compact R-active state. The latter is tagged as "R-like" T-inactive (Fig. 7). Each conformer was shown to be populated by a multiplicity of discrete conformational sub-states that interconvert on fast time scales, as detected by our experiments. Assuming that $100 \%$ of the Tt LDH tetramer is chemically modified after irradiation, all these conformers present in solution corresponds to an ensemble of inactive forms that are not able to reach the "true" R-active state by homotropic activation at high temperature. It is now well accepted that allosteric regulation of enzymes is the result of a large spectrum of dynamical and conformational diversities (Motlagh et al., 2014; Xu and Chance, 2007). In this framework, all the conformers of an enzyme are populated with respect to their energies. Any modification such as temperature, solvent properties, mutations, allosteric ligand binding etc., will therefore resample the energetic and conformational landscape of an allosteric enzyme. In 


\section{T-inactive: two states in equilibrium}
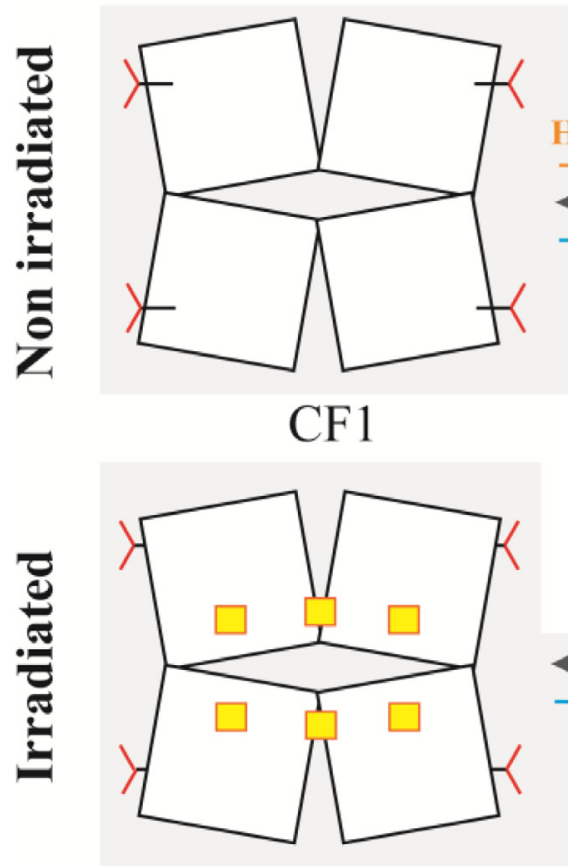

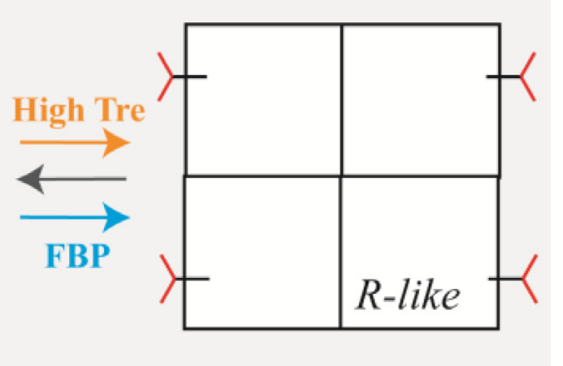

CF2

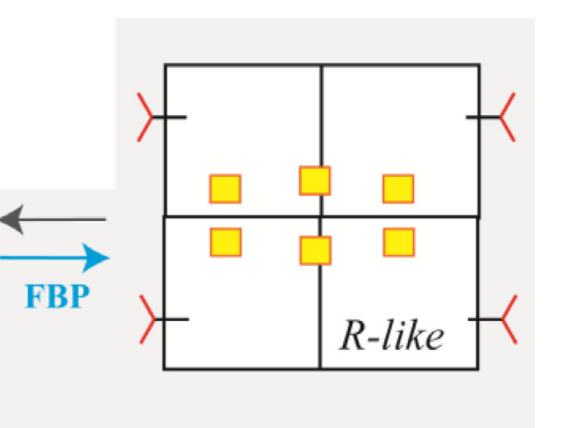

R-active
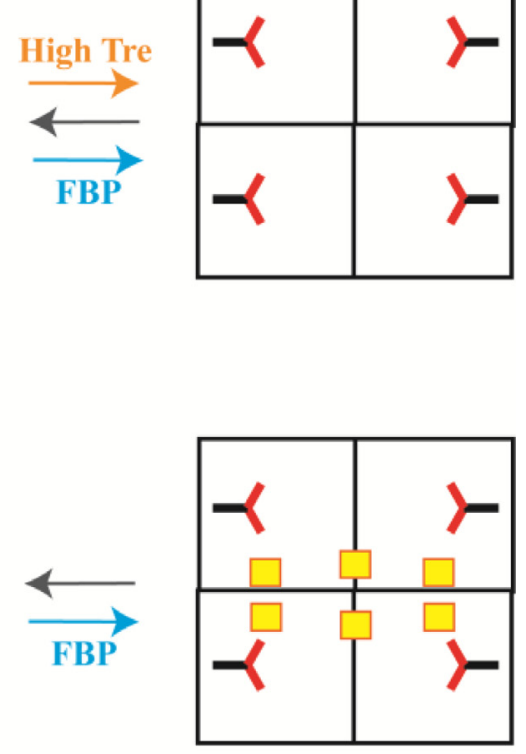

Fig. 7. Concluding scheme of the allostery mechanism in $T t \mathrm{LDH}$ with respect to oxidative stress. The scheme depicts the equilibrium between the T-and R-states of $T t$ LDH in solution. Before irradiation, two conformers (CF1 and CF2) of various sizes populate the T-state. The most compact looks like the R-state. Monomers are illustrated by squares, in which the substrate binding residue R171 (small red anchor) is oriented outside the catalytic site. High temperature or FBP binding change the equilibrium toward the R-active compact tetrameric state and favors R171 to enter the catalytic site. After irradiation, T-conformers are chemically modified (small orange squares), preventing activation by high temperature.

line with this assumption, our study unveiled the existence of "frozen" inactive conformers induced by chemical modifications, which are slightly different from those described by crystallographic studies. In agreement with the concept of structural diversity we showed in a previous study, using crystallography and molecular dynamics simulations on Tt LDH mutants, that the enzyme can adopt local intermediate conformations in between the T-inactive and R-active states (Colletier et al., 2012). It was analyzed that the interface between monomers A and B delineates a tunnel in which the side chain of R171 should slide during the reorganization from the T-inactive to the Ractive state. During the reorganization, the neighboring residues R171 and $\mathrm{H} 68$ from helix $\alpha \mathrm{C}$ of monomer B displayed coordinated side chain movements (Colletier et al., 2012). Calculations showed there is a local high-energy barrier which should be jumped to favor the R171 side chain in the R-state (Colletier et al., 2012). Analysis of Tt LDH structure has revealed that helix $\alpha 2 \mathrm{~F}$ is a hinge region, which undergoes a conformational reorganization upon catalysis. We can reasonably propose that the ROS modifications, which target amino acids located on helix $\alpha 2 \mathrm{~F}$ and those, which modified $\mathrm{H} 68$ on helix $\alpha \mathrm{C}$ have induced unfavorable steric hindrances. Consequently, these contacts have increased the population of conformers with a higher energy barrier than with the non-irradiated enzyme. A situation that prevents the populations of T-inactive and "R-like" inactive states to reach the R-state (Fig. 7).

Heterotrophic activation of allosteric LDH by FBP is well described (Iwata and Ohta, 1993; Taguchi, 2017). It implies the binding of two FBP molecules between subunits of the tetramer. In all allosteric LDHs, residues involved in the FBP binding site i.e. R173, H188 and Y190 are strictly conserved (Iwata and Ohta, 1993; Madern, 2002; Taguchi, 2017). These residues are shown in sticks in Fig. 4. FBP binding triggers sliding of a helix between subunits, inducing a $180^{\circ}$ rotation of the substrate-binding residue R171 within the catalytic site; a structural reorganization that is specific of the R- active state of LDH. We established that after irradiation, even if all Tt LDH conformers are "frozen" in non-competent states for catalysis, none of the important residues involved in catalysis were damaged. Therefore, because the area, which helps to make the FBP binding site at the P axis (including R173, H188 and Y190), is not impacted by ROS, the binding of the allosteric ligand FBP provided a favorable binding energy that changed the energy landscape of the ROS-damaged conformers toward competent states for catalysis.

To date, very few studies on the effects of ROS on LDHs have been reported (Buchanan and Armstrong, 1976; Rodacka et al., 2019). They used eukaryotic LDH-A from rabbit as a model. With this enzyme, the loss of activity is the consequence of hydroxyl radical attack on a cysteine (C165) that does not belong to the catalytic site. With the rabbit $\mathrm{LDH}$, it was postulated that conformational changes might affect the susceptibility of this cysteine to ROS, in particular, through the formation of the ternary (NADH-substrate-enzyme) complex which would be more resistant (Buchanan and Armstrong, 1976; Monod et al., 1965; Saito, 1978; Van der Rest et al., 2017). However, this statement remains a source of controversy because this residue is not conserved in all LDHs. Inspection of the rabbit LDH structure (PDB code 3H3F) shows the cysteine is a buried residue located in the second sphere of neighboring amino acid residues constituting the catalytic site. Its side chain is in Van der Waals contact with the main chain of the catalytic histidine H195, strongly suggesting that changes in local fluctuations by virtue of ROS attack impact the catalytic site geometry required to achieve catalysis.

We noticed that the Cys165 in rabbit LDH was located on the same mobile helix $\alpha 2 \mathrm{~F}$ as in $T t$ LDH for which we found that ROS damaged amino acids were responsible for the inhibition. In addition, two recent studies using rabbit LDH have shown that the enzyme may sample a conformational landscape like the one of allosteric enzymes 
(Hernandez-Meza and Sampedro, 2018; Katava et al., 2017). Very few studies report reversible alterations of proteins after ROS damage. In all the cases it was shown to be the consequence of the oxidation state of cysteine residue involved in disulfide bond formation (Chakraborty et al., 2018; Machado et al., 2017). Hence, our work and previous studies using LDHs show that conformational dynamics plays an important role in radiation-induced enzyme inactivation.

\section{CRediT authorship contribution statement}

Frédéric Halgand: Investigation, Methodology, Software, Formal analysis, Writing - original draft, Writing - review \& editing. Chantal Houée-Lévin: Investigation, Methodology, Formal analysis, Writing review \& editing. Martin Weik: Funding acquisition, Conceptualization, Writing - review \& editing. Dominique Madern: Funding acquisition, Conceptualization, Supervision, Methodology, Investigation, Formal analysis, Writing - original draft, Writing - review \& editing.

\section{Declaration of Competing Interest}

The authors declare that they have no known competing financial interests or personal relationships that could have appeared to influence the work reported in this paper.

\section{Acknowledgements}

The authors acknowledge funding by the Ile-de-France DIM Analytics program for the MOBICS project and ANR grants to MW (JC05_45684 2006; Radiodommages) and to DM (ANR-16-CE11-0011; AlloAnc). This project has received financial support from the CNRS through the MITI interdisciplinary programs.

\section{Appendix A. Supplementary data}

Supplementary data to this article can be found online at https:// doi.org/10.1016/j.jsb.2020.107478.

\section{References}

Alvarez, L., Houée-Levin, C., Merola, F., Bizouarn, T., Pasquier, H., Baciou, L., Rusconi, F., Erard, M., 2010. Are the fluorescent properties of the cyan fluorescent protein sensitive to conditions of oxidative stress? Photochem. Photobiol. 86, 55-61.

Aruoma, O.I., Kaur, H., Halliwell, B., 1991. Oxygen free radicals and human diseases. J. R. Soc. Health 111, 172-177.

Aruoma, O.I., Grootveld, M., Bahorun, T., 2006. Free radicals in biology and medicine: from inflammation to biotechnology. BioFactors 27, 1-3.

Avery, S.V., 2011. Molecular targets of oxidative stress. Biochem. J. 434, 201-210.

Bagautdinov, B., Yutani, K., 2011. Structure of indole-3-glycerol phosphate synthase from Thermus thermophilus HB8: implications for thermal stability. Acta Crystallogr. D Biol. Crystallogr. 67, 1054-1064.

Ban, X., Lahiri, P., Dhoble, A.S., Li, D., Gu, Z., Li, C., Cheng, L., Hong, Y., Li, Z., Kaustubh, B., 2019. Evolutionary stability of salt bridges hints its contribution to stability of proteins. Comput. Struct. Biotechnol. J. 17, 895-903.

Beveridge, R., Covill, S., Pacholarz, K.J., Kalapothakis, J.M., MacPhee, C.E., Barran, P.E., 2014. A mass-spectrometry-based framework to define the extent of disorder in proteins. Anal. Chem. 86, 10979-10991.

Beveridge, R., Migas, L.G., Payne, K.A., Scrutton, N.S., Leys, D., Barran, P.E., 2016. Mass spectrometry locates local and allosteric conformational changes that occur on cofactor binding. Nat. Commun. 7, 12163.

Bobrowski, K., 2017. Radiation chemistry of liquid systems., p. 81-116, Y. Sun and A.G. Chmielewski (Eds.), Application of Ionizing Radiation in Materials Processing. Institute of Nuclear Chemistry and Technology, Warszawa.

Brun, E., Blouquit, Y., Duchambon, P., Malosse, C., Chamot-Rooke, J., Sicard-Roselli, C., 2010. Oxidative stress induces mainly human centrin 2 polymerisation. Int. J. Radiat. Biol. 86, 657-668.

Buchanan, J.D., Armstrong, D.A., 1976. Free radical inactivation of lactate dehydrogenase. Int. J. Radiat. Biol. Relat. Stud. Phys. Chem. Med. 30, 115-127.

Bush, M.F., Campuzano, I.D., Robinson, C.V., 2012. Ion mobility mass spectrometry of peptide ions: effects of drift gas and calibration strategies. Anal. Chem. 84, 7124-7130.

Cecarini, V., Gee, J., Fioretti, E., Amici, M., Angeletti, M., Eleuteri, A.M., Keller, J.N., 2007. Protein oxidation and cellular homeostasis: emphasis on metabolism. Biochim.
Biophys. Acta, Protein Struct. Mol. Enzymol. 1773, 93-104.

Chakraborty, S., Ganguli, S., Chowdhury, A., Ibba, M., Banerjee, R., 2018. Reversible inactivation of yeast mitochondrial phenylalanyl-tRNA synthetase under oxidative stress. Biochim. Biophys. Acta, Gen. Subj. 1862, 1801-1809.

Cheignon, C., Tomas, M., Bonnefont-Rousselot, D., Faller, P., Hureau, C., Collin, F., 2018 Oxidative stress and the amyloid beta peptide in Alzheimer's disease. Redox Biol. 14 450-464.

Colletier, J.P., Aleksandrov, A., Coquelle, N., Mraihi, S., Mendoza-Barbera, E., Field, M., Madern, D., 2012. Sampling the conformational energy landscape of a hyperthermophilic protein by engineering key substitutions. Mol. Biol. Evol. 29, 1683-1694.

Coquelle, N., Fioravanti, E., Weik, M., Vellieux, F., Madern, D., 2007. Activity, stability and structural studies of lactate dehydrogenases adapted to extreme thermal environments. J. Mol. Biol. 374, 547-562.

Et Taouil, A., Brun, E., Duchambon, P., Blouquit, Y., Gilles, M., Maisonhaute, E., SicardRoselli, C., 2014. How protein structure affects redox reactivity: example of Human centrin 2. Phys. Chem. Chem. Phys. 16, 24493-24498.

Feldman-Salit, A., Hering, S., Messiha, H.L., Veith, N., Cojocaru, V., Sieg, A., Westerhoff, H.V., Kreikemeyer, B., Wade, R.C., Fiedler, T., 2013. Regulation of the activity of lactate dehydrogenases from four lactic acid bacteria. J. Biol. Chem. 288, 21295-21306.

Garcia, A.K., Kacar, B., 2019. How to resurrect ancestral proteins as proxies for ancient biogeochemistry. Free Radic. Biol. Med. 140, 260-269.

Halliwell, B., Gutteridge, J.M.C., 1999. Free Radicals and Biology and Medicine., p. 1-25, Halliwell, B. and Gutteridge, J.M.C., Eds., Free Radicals and Biology and Medicine, 3rd Edition., Oxford University Press, Oxford.

Hardy, M., Zielonka, J., Karoui, H., Sikora, A., Michalski, R., Podsiadly, R., Lopez, M., Vasquez-Vivar, J., Kalyanaraman, B., Ouari, O., 2018. Detection and characterization of reactive oxygen and nitrogen species in biological systems by monitoring speciesspecific products. Antioxid. Redox Signal. 28, 1416-1432.

Heck, A.J., 2008. Native mass spectrometry: a bridge between interactomics and structural biology. Nat. Methods 5, 927-933.

Hernandez-Meza, J.M., Sampedro, J.G., 2018. Trehalose mediated inhibition of lactate dehydrogenase from rabbit muscle. The application of Kramers' theory in enzyme catalysis. J. Phys. Chem. B 122, 4309-4317.

Hicks, M., Gebicki, J.M., 1986. Rate constants for reaction of hydroxyl radicals with Tris, Tricine and Hepes buffers. FEBS Lett. 199, 92-94.

Houée-Levin, C., Bobrowski, K., 2013. The use of the methods of radiolysis to explore the mechanisms of free radical modifications in proteins. J. Proteomics 92, 51-62.

Iwata, S., Ohta, T., 1993. Molecular basis of allosteric activation of bacterial L-lactate dehydrogenase. J. Mol. Biol. 230, 21-27.

Jurneczko, E., Barran, P.E., 2011. How useful is ion mobility mass spectrometry for structural biology? The relationship between protein crystal structures and their collision cross sections in the gas phase. Analyst 136, 20-28.

Kadlick, V., Sicard-Roselli, C., Kodicek, M., Houée-Levin, C., 2004. One-electron oxidation of beta-amyloid peptide: sequence modulation of reactivity. Free Rad. Biol. Med. 37, $881-891$.

Kalimeri, M., Girard, E., Madern, D., Sterpone, F., 2014. Interface matters: the stiffness route to stability of a thermophilic tetrameric malate dehydrogenase. PLoS ONE 9, e113895.

Kalyanaraman, B., Cheng, G., Hardy, M., Ouari, O., Bennett, B., Zielonka, J., 2018. Teaching the basics of reactive oxygen species and their relevance to cancer biology: mitochondrial reactive oxygen species detection, redox signaling, and targeted therapies. Redox Biol. 15, 347-362.

Karshikoff, A., Ladenstein, R., 2001. Ion pairs and the thermotolerance of proteins from hyperthermophiles: a "traffic rule" for hot roads. Trends Biochem. Sci. 26, 550-556.

Katava, M., Maccarini, M., Villain, G., Paciaroni, A., Sztucki, M., Ivanova, O., Madern, D. Sterpone, F., 2017. Thermal activation of 'allosteric-like' large-scale motions in a eukaryotic Lactate Dehydrogenase. Sci. Rep. 7, 41092.

Krisko, A., Radman, M., 2013. Biology of extreme radiation resistance: the way of Deinococcus radiodurans. Cold Spring Harb. Perspect. Biol. 5.

Luke, K.A., Higgins, C.L., Wittung-Stafshede, P., 2007. Thermodynamic stability and folding of proteins from hyperthermophilic organisms. FEBS J. 274, 4023-4033.

Lunine, J.I., 2006. Physical conditions on the early Earth. Philos. Trans. R. Soc. Lond. B Biol. Sci. 361, 1721-1731.

Machado, L., Shen, T.L., Page, R., Peti, W., 2017. The KIM-family protein-tyrosine phosphatases use distinct reversible oxidation intermediates: Intramolecular or intermolecular disulfide bond formation. J. Biol. Chem. 292, 8786-8796.

Madern, D., 2002. Molecular evolution within the L-malate and L-lactate dehydrogenase super-family. J. Mol. Evol. 54, 825-840.

McCullough, B.J., Kalapothakis, J., Eastwood, H., Kemper, P., MacMillan, D., Taylor, K. Dorin, J., Barran, P.E., 2008. Development of an ion mobility quadrupole time of flight mass spectrometer. Anal. Chem. 80, 6336-6344.

Monod, J., Wyman, J., Changeux, J.P., 1965. On the nature of allosteric transitions: a plausible model. J. Mol. Biol. 12, 88-118.

Motlagh, H.N., Wrabl, J.O., Li, J., Hilser, V.J., 2014. The ensemble nature of allostery. Nature 508, 331-339.

Nisbet, E.G., Sleep, N.H., 2001. The habitat and nature of early life. Nature 409, 1083-1091.

Ranawat, P., Rawat, S., 2017. Radiation resistance in thermophiles: mechanisms and applications. World J. Microbiol. Biotechnol. 33, 112.

Requena, J.R., Dimitrova, M.N., Legname, G., Teijeira, S., Prusiner, S.B., Levine, R.L., 2004. Oxidation of methionine residues in the prion protein by hydrogen peroxide. Arch. Biochem. Biophys. 432, 188-195.

Rodacka, A., Strumillo, J., Puchala, M., Serafin, E., Bartosz, G., 2019. Comparison of protective properties of resveratrol and melatonin in the radiation inactivation and 
destruction of glyceraldehyde-3-phosphate dehydrogenase and lactate dehydrogenase. Int. J. Radiat Biol. 1-12.

Rothschild, L.J., Mancinelli, R.L., 2001. Life in extreme environments. Nature 409, 1092-1101.

Saito, M., 1978. Coenzyme protection of lactic dehydrogenase against inactivation by gamma-rays. Int. J. Radiat. Biol. Relat. Stud. Phys. Chem. Med. 34, 95-99.

Salbo, R., Bush, M.F., Naver, H., Campuzano, I., Robinson, C.V., Pettersson, I., Jorgensen, T.J., Haselmann, K.F., 2012. Traveling-wave ion mobility mass spectrometry of protein complexes: accurate calibrated collision cross-sections of human insulin oligomers. Rapid Commun. Mass Spectrom. 26, 1181-1193.

Scarff, C.A., Thalassinos, K., Hilton, G.R., Scrivens, J.H., 2008. Travelling wave ion mobility mass spectrometry studies of protein structure: biological significance and comparison with X-ray crystallography and nuclear magnetic resonance spectroscopy measurements. Rapid Commun. Mass Spectrom. 22, 3297-3304.

Spinks, J.W.T., Woods, R.J., 1990. An introduction to radiation chemistry. United States: John Wiley and Sons Inc.

Sun, Y., Vahidi, S., Sowole, M.A., Konermann, L., 2016. Protein structural studies by traveling wave ion mobility spectrometry: a critical look at electrospray sources and calibration issues. J. Am. Soc. Mass Spectrom. 27, 31-40.
Taguchi, H., 2017. The simple and unique allosteric machinery of Thermus caldophilus lactate dehydrogenase: structure-function relationship in bacterial allosteric LDHs. Adv. Exp. Med. Biol. 925, 117-145.

Van der Rest, G., Rezaei, H., Halgand, F., 2017. Monitoring conformational landscape of ovine prion protein monomer using ion mobility coupled to mass spectrometry. J. Am. Soc. Mass Spectrom. 28, 303-314.

Vogt, W., 1995. Oxidation of methionyl residues in proteins: tools, targets, and reversal. Free Radic. Biol. Med. 18, 93-105.

von Sonntag, C., 2008. Advanced oxidation processes: mechanistic aspects. Water Sci. Technol. 58, 1015-1021.

Wolschner, C., Giese, A., Kretzschmar, H.A., Huber, R., Moroder, L., Budisa, N., 2009. Design of anti- and pro-aggregation variants to assess the effects of methionine oxidation in human prion protein. Proc. Natl. Acad. Sci. U.S.A. 106, 7756-7761.

Xu, G., Chance, M.R., 2007. Hydroxyl radical-mediated modification of proteins as probes for structural proteomics. Chem. Rev. 107, 3514-3543.

Yan, L.J., Sumien, N., Thangthaeng, N., Forster, M.J., 2013. Reversible inactivation of dihydrolipoamide dehydrogenase by mitochondrial hydrogen peroxide. Free Radic. Res. 47, 123-133. 